\title{
An Experimental Test of Design Alternatives for the British 3G / UMTS Auction
}

\author{
by KLAUS ABBINK*, BERND IRLENBUSCH ${ }^{* *}$, \\ PAUL PEZANIS-CHRISTOU ${ }^{* * * * * *}$, BETTINA ROCKENBACH ${ }^{* * *}$, \\ ABDOLKARIM SADRIEH $^{* * * *}$, and REINHARD SELTEN ${ }^{* * *}$ \\ * University of Nottingham \\ ** University of Erfurt \\ *** Institut d'Anàlisi Econòmica CSIC and Universitat Pompeu Fabra, Barcelona \\ $* * * * \quad$ Tilburg University \\ $* * * * * \quad$ University of Bonn
}

September 2001

\begin{abstract}
In spring 2000, the British government auctioned off licences for Third Generation mobile telecommunications services. In the preparation of the auction, two designs involving each a hybrid of an English and a sealed-bid auction were suggested by the government: a discriminatory and a uniform price variant. We report an experiment on these two designs, and also compare the results to those with a pure English auction. Both hybrids are similar in efficiency, revenue differences disappear as bidders get experienced. Compared to the discriminatory format, the pure English auction gives new entrants better chances.
\end{abstract}

\section{Keywords}

Spectrum auctions, UMTS, experiments

\section{JEL Classification Codes}

C90, D44

\section{Acknowledgements}

We thank Dan Maldoom and Toby Robertson at London Economics Ltd for their valuable help in preparing the experiments and for the co-ordination and communication between our respective teams, as well as Sean Lyons for post-project support. We also thank Ken Binmore and Paul Klemperer for helpful comments and suggestions. All errors remain our own. Financial support by London Economics Ltd, the Deutsche Forschungsgemeinschaft through the Sonderforschungsbereich 303, the European Union through the TMR research network ENDEAR (FMRX-CT98-0238) and the Marie Curie Fellowship HPMF-CT-199-00312 (Sadrieh), and the Land NordrheinWestfalen is gratefully acknowledged. The views expressed in this paper are our own and should not be attributed to any party involved in the British 3G/ UMTS licence auction. 


\section{Author Addresses}

\section{Klaus Abbink}

School of Economics

The University of Nottingham

University Park

Nottingham, NG7 2RD

United Kingdom

Tel. +44-115-951-4768

Fax +44-115-951-4159

klaus.abbink@nottingham.ac.uk

\section{Bernd Irlenbusch, Bettina Rockenbach}

Lehrstuhl für Mikroökonomie

Universität Erfurt

Nordhäuser Str. 63

99089 Erfurt

Germany

Tel. +49-361-737-4523 (Irlenbusch)

+49-361-737-4521 (Rockenbach)

Fax +49-361-737-4529

bernd.irlenbusch@uni-erfurt.de

bettina.rockenbach@uni-erfurt.de

\section{Paul Pezanis-Christou}

Institut d'Anàlisi Econòmica CSIC

Campus UAB

08193 Bellaterra (Barcelona)

Spain

Tel. +34-93-580-6612

Fax +34-93-580-1452

paul.pezanis@econ.upf.es

\section{Abdolkarim Sadrieh}

Department of Economics and CentER

Tilburg University

PO Box 90153

5000 LE Tilburg

The Netherlands

Tel. +31-13-466-2938

Fax +31-13-466-3042

sadrieh@kub.nl

\section{Reinhard Selten}

Laboratorium für experimentelle Wirtschaftsforschung Universität Bonn

Adenauerallee 24-42

53113 Bonn

Germany

Tel. +49-228-73-9195

Fax +49-228-73-9193

selten@lab.econ1.uni-bonn.de 


\section{Introduction}

In April 2000, a spectacular auction took place in Great Britain. Five licences to operate UMTS mobile telephony (or more generally $3 \mathrm{G}$ services ${ }^{1}$ ) were put up for sale and generated a total revenue of more than 22 billion British pounds. Such a figure established a new record in the history of spectrum auctions until it was topped by the UMTS / IMT-2000 auction in Germany four months later. The widespread enthusiasm about UMTS comes from the data transfer rates it offers (up to 2 MBits per second) which are 200 times faster than the current $2 \mathrm{G}$ ("Second Generation") standards like GSM. With such a speed, UMTS can combine the world of mobile telephony with the world of the Internet. Moreover, the new standard is powerful enough to allow for downloading motion pictures in real-time or holding videoconferences via mobile phone.

The 3G/UMTS auction in the United Kingdom was held by the British Radiocommunications Agency (RA). The event was preceded by extensive discussions between RA and the potential participants over the packaging of frequencies and the design of the auction. Radio frequencies are a scarce resource. In line with international agreements, the British government reserved 2x60 MHz paired spectrum and 1x20 MHz unpaired spectrum for $3 \mathrm{G}$ services. In 1998, RA initially proposed to package these frequencies into four almost homogeneous licences of 2x15 MHz paired spectrum and 1x5 MHz unpaired spectrum each. ${ }^{2}$ Next to the packaging, the auction design was discussed. RA proposed to use one of two auction designs that were both based on the Anglo-Dutch concept developed by KLEMPERER (1998), who was one of the advisors of the UK government. These Anglo-Dutch auctions are hybrids consisting of an ascending bid ("English") first part and a sealed-bid ("Dutch") second part. In the first part, the price for a licence is increased until all but five bidders have quit the auction. In the second stage, each of the remaining five bidders submits only one best and final offer, where their bid must be at least as high as the last prevailing price of the first stage. The licences are then sold to the four highest bidders. The two formats differ in the price successful bidders pay. In the discriminatory Anglo-Dutch auction, the four winners pay their respective bids. In the uniform Anglo-Dutch auction all four winners pay the lowest winning bid. ${ }^{3}$

\footnotetext{
${ }^{1} 3 \mathrm{G}$ - "Third Generation" - is the generic term for broadband mobile communications systems according to the IMT-2000 standard of the International Telecommunications Union (ITU). The Universal Mobile Telecommunications System (UMTS) is one of the systems of the IMT-2000 family. In the public discussion, UMTS is often used as a synonym for $3 \mathrm{G}$ services, since most operators in Europe are expected to use this system.

${ }^{2}$ Later, RA decided to divide the available spectrum into five heterogeneous licences (see section 7).

${ }^{3}$ A third stage was provided to allocate the licences to the bidders. This was necessary because there might have been slight differences between the licences, mainly with respect to the position of spectrum in the frequency range. However, since these differences were expected to be minor, we do not consider this stage in the following.
} 
Potential auction participants were asked to express their views on the proposed designs. In this paper, we report the outcomes of a laboratory experiment that was part of an extensive economic analysis commissioned by a potential bidder, before putting forward comments on the auction design to RA. In our experiment, we compare the two proposed Anglo-Dutch auction designs to one another and, further, to a pure ascending auction format in which the first stage is extended until all but the four final winners have withdrawn. The latter is a more traditional format similar to those used in previous spectrum auctions in other countries. In our experiment, we observe that both Anglo-Dutch formats are very similar in terms of efficiency, revenue, and entry possibilities, which reflect the major goals of the UK government. Both formats also lead to outcomes comparable to those of the ascending auction. We observe the highest number of successful new entrants in the ascending auction.

\section{Background}

The Anglo-Dutch concept proposed for the British 3G/ UMTS auction was a novelty for spectrum auctions. Most previous auctions for radio frequencies have used multi-round simultaneous bid designs inspired by the US spectrum auctions held by the Federal Communications Commission (FCC). ${ }^{4}$ In these auctions, participants submit bids for the items for sale (spectrum blocks or complete licences) in simultaneous bidding rounds. In these bidding rounds, the bidders submitting the highest bids are the current holders of the items. When no new bids are submitted, the auction ends and the holders at the end of the auction are awarded their respective items.

For the allocation of the $3 \mathrm{G}$ licences in Great Britain, RA was reluctant to use such an ascending auction format. This reluctance was based on the coincidence that four incumbents (Vodafone, British Telecom, Orange, and One2One) were present on the current UK mobile telephony market, and also four licences for the new technology were to be auctioned. RA assessed that the current incumbents were very likely to be stronger bidders with higher valuations for the licences than the new entrants. Therefore, RA was worried that the four incumbents might receive the four licences without facing strong competition by new operators. An ascending auction format was conjectured to be especially discouraging for new entrants. Because the British government intended to encourage market entry, RA was very concerned about such effects. Obviously, also the revenue raised in the auction would be unsatisfactory if all new entrants withdrew from the auction very early.

Because of their complexity, spectrum auction environments are generally not conducive to a thorough game theoretic treatment. Nevertheless, by considering much simpler and therefore more tractable set-ups, auction theory provides some examples that support concerns about early drop-out effects to some extent. KLEMPERER (1998) spells out the Wallet Game, in

\footnotetext{
${ }^{4}$ For discussions of the FCC auctions and its European successors see MCMILlAN (1994), CRAMTON (1995), MCAFEe, and MCMillan (1996), Ausubel, Cramton, MCAFEe, and MCMillan (1997), Keuter and NetT (1997), SALANT (1997), VAN DAMME (1999).
} 
which two players bid for a single item in an ascending auction. The common (unknown) value equals the sum of the two bidders' signals ("wallets"). The special feature in the variant KLEMPERER (1998) introduces is that both bidders know that one of them will for sure have a small additional private value no matter which common value is realised. Because of the payoff advantage, the stronger bidder can bid more aggressively, which forces the weaker bidder to bid even more cautiously in order to avoid a loss. The more cautious the behaviour of the weaker bidder, however, the more aggressively the advantaged bidder can bid in this constellation. In equilibrium, the weaker bidder never outbids the stronger bidder, because he would make a loss in that case. ${ }^{5}$

BIKHCHANDANI (1988) shows that a similar phenomenon can arise in second price auctions, which are strategically equivalent to ascending auctions in the case of two bidders. In his model, one of the two buyers assigns a greater value to the asset than the other buyer with a positive probability. In BIKHCHANDANI's setting the stronger bidder can credibly establish a reputation for being "tough", and the weaker bidder rationally refrains from serious competition. ${ }^{6}$ In a different setting, ROBINSON (1985) shows that both in common value and private value settings "collusive" equilibria with "early drop-outs" exist. Weaker bidders never win the auction, thus they do not lose anything by quitting early. When they do so, the stronger bidder gets the item for a very low price. These early drop-out equilibria, however, are not frequently played in experiments conducted by KAMECKE (1998a). While in ROBINSON's setting these are equilibria in weakly dominated strategies, KAMECKE (1998b) constructs a more complex variant of ROBINSON's set-up, in which an iterated application of the dominance criteria does not lead to the elimination of "early drop-out" equilibria.

The Anglo-Dutch formats, as proposed for the 3G/ UMTS auction in the United Kingdom, were intended to alleviate the problem of early drop-outs. The final allocation of the items for sale to the bidders is determined in a sealed bid stage, which consists of only one bidding round. This sealed bid stage would cure the problem of low revenue equilibria in the simple theoretical examples mentioned above. On the other hand, the Anglo-Dutch auctions maintain an ascending first stage to preserve the transparency of ascending auctions to some extent.

The question arises whether the drop-out problem would also prevail in an environment more akin to the British 3G/ UMTS scenario than the simple examples available. There are reasons to believe that the empirically relevant auction framework is more complex in a number of dimensions. Concerning bidders' valuations, for example, GOEREE and OFFERMAN (2001) observe that "most real world auctions exhibit both private and common value elements." Further, it is also quite likely to observe more than just one-sided uncertainty about bidders' types. Given such complexities, it is not clear at all that the received predictions on the dropout problem hold. For example, DE FRUTOS and PECHLIVANOS (2001) show that the drop-out problem in the BIKHCHANDANI (1988) framework disappears when uncertainty about the

\footnotetext{
5 See also BUlOw, HUANG, and KlemPERER (1998). BUlOW and KLEMPERER (2000) extend this game to three bidders and obtain some similar results.

${ }^{6}$ In their experiments, however, AVERY and KAGEL (1995) find this effect to be weaker than predicted.
} 
bidders' types is two-sided, because in the equilibrium the weak bidder has a strictly positive probability of winning. Given the contradictory results of the above mentioned models, general assertions on auctions with asymmetries seem difficult to make. Therefore, great caution should be taken when projecting these results onto richer environments such as the one under consideration.

London Economics Ltd., the consultancy advising one of the potential bidders, approached us for an experimental study to complement the preparations of the bidder's submission to RA. Among the two suggested designs, the bidder a priori believed that the uniform variant would be more favourable. Next to experiments on these Anglo-Dutch variants, we also conducted experiments on a pure ascending format. The bidder favoured such a simple ascending design most, but it was not considered by the UK government at that stage of the decision making process. We designed and examined a model that on the one hand is simple enough to allow experimentation, but on the other hand is rich enough to capture the most important features characterising the British spectrum auction environment. The model was developed in close co-operation with London Economics. In this paper we present the results of the experimental examination. $^{7}$

\section{The Valuation Model}

A crucial factor in the analysis of auction design is the way in which the value of the objects to the bidders is modelled. In the theoretical and experimental literature on auctions, two main streams have evolved. In independent private value models, each bidder knows his own valuation, but not the valuations of the other bidders. Additionally, the distribution from which all bidders' values are drawn is (usually) common knowledge. All private values are drawn independently, either from the same distribution (symmetric case), or from different distributions for different bidders (asymmetric case). Examples for independent private value models are perishable goods auctions, such as flowers, vegetables and fish auctions. Generally, this model is well-suited for situations in which a bidder's willingness-to-pay solely depends on his personal traits.

The other main type of valuation model is the common value model. In a common value auction, the value of an item is the same for all bidders, but not known at the time of the auction. Before the auction each bidder receives an estimate (a signal) drawn from some distribution around the true value. The classical example of a common value auction is the auctioning of oil drilling rights. In these auctions the value of the licence almost only depends

\footnotetext{
${ }^{7}$ At the time our experimental study was conducted, no other experimental data set in a related framework was available. RA had commissioned experiments on the two Anglo-Dutch auction formats that were conducted in parallel to ours by Ken Binmore. Details of the design and the results were not made public because of confidentiality concerns, but according to KLEMPERER (2000), the main finding of these experiments was that both hybrids perform well. To our knowledge, a comparison with ascending designs was not made. Earlier experiments concerned with spectrum auctions are hardly comparable, since the experiments have been customised to the particular auction design and environment under consideration (PLOTT 1997).
} 
on the quantity of oil in the corresponding field. The signal bidders in these auctions typically have are the estimations in their geological reports. A well-known phenomenon in connection with common value auctions, which is both empirically and experimentally observed, is the so-called winner's curse. ${ }^{8}$ Often the winning bidder overpays the true value of the item. This is so, since bidders naturally tend to bid higher, the higher their estimate for the item is. As a result, the bidder who over-estimates the true value most, wins the auction and pays more than the average signal and, thus, often more than the actual value of the item.

For the valuation of a $3 \mathrm{G}$ licence, features of both models can be identified. The common value component arises because for all buyers profit prospects are affected by the development of the UMTS market as a whole. Since the technology is new (even the products supplied with UMTS are largely unknown at present), judgement errors can lead to a considerable potential for the winner's curse. A private value component is present since the expected profits of a single UMTS provider depend on the potential of its business concept. Operators already active in GSM services (the incumbents) may face better initial conditions than new entrants, therefore the private value component is asymmetric. The advantages mainly stem from the incumbents' existing pool of GSM subscribers, who can be attracted to UMTS. Incumbents not only have a better access to customers, but also to existing installations and the corresponding human capital. Further determinants of a bidder's private value are the extent to which a UK licence contributes to the global business strategy of a company, potentially non-rational expectations of shareholders (especially if a company is to be sold or plans public offering after the auction), and synergy effects with a company's other activities (e.g. Internet and multimedia services). ${ }^{9}$

We model a bidder's valuation of a licence as the sum of the common value component ( $c v c)$, representing the component arising from the market potential of UMTS, and a private value component $(p v c)$, representing advantages or disadvantages of single operators. ${ }^{10} \mathrm{We}$ conducted the experimental auctions with eight bidders. ${ }^{11}$ The $c v c$ is identical for all bidders, randomly drawn from the integers in the interval [1000,1500]. The bidders are neither informed about the random draw of the $c v c$ nor about the interval from which it is drawn. However, each bidder receives an independent private signal on the $c v c$ and is informed about

\footnotetext{
${ }^{8}$ The winner's curse phenomenon was first reported in an empirical study on oil field auctions by CAPEN, ClAPP, and CAMPBELL (1971). A quote in CASSADY (1967, p.29) suggests that the winner's curse was already identified by buddhist monks in $7 \mathrm{AD}$. "When the personal belongings of deceased monks were auctioned off and the bidding went too high, the monk who acted as the auctioneer reminded his fellow monks: Better be thoughtful. You might regret it later." Numerous experimental studies have examined this phenomenon, beginning with KAGEL and LEVIN (1986, for an overview see KAGEL 1995).

9 For a detailed description of the UK mobile telecommunications market see VALLETTI and CAVE (1998).

${ }^{10}$ GOEREE and OFFERMAN (2001) consider a similar model to study the efficiency properties of mixed valuation first-price auctions. They report experimental evidence showing that the presence of a common value component in bidders' valuations decreases efficiency, as theoretically predicted.

${ }^{11}$ It was expected that 9 or 10 bidders would participate in the UK UMTS auction (it turned out to be 13). However, space and time constraints required to reduce the number of participants. We do not think that adding more weak bidders would change the results dramatically.
} 
the fact that these signals are determined by uniform random draws from the integers in the interval [cvc-200, $c v c+200]$.

The $p v c$ of each bidder is an integer number, randomly determined between -100 and +100 , inclusively. The underlying distribution for the $p v c$ draw depends on the bidder's type, which can be either INC or NEW. Four INC-type bidders represent the four incumbents on the British GSM market, the four NEW-type bidders represent four new entrants. For simplicity, we make no further distinctions within the set of incumbents and within the set of new entrants. Each bidder is informed about the types of all bidders and his/her own $p v c$.

A bidder of type INC has a $p v c$, which is drawn uniformly from the interval $[0, \ldots,+100]$ with an 80 percent chance and drawn uniformly from the interval $[-100, \ldots, 0]$ with the remaining 20 percent chance. A bidder of type $\mathrm{N}$ has a $p v c$, which is drawn uniformly from the interval $[0, \ldots,+100]$ with a 20 percent probability and drawn uniformly from the interval $[-100, \ldots, 0]$ with the remaining 80 percent probability. The high probability of the INC-type bidders to have a positive $p v c$ reflects the advantages of the incumbents. Nevertheless, it is not impossible that a new entrant receives a high private value component as well. The idea is that private advantages can come from many sources and not all of them are attributable to incumbents only. ${ }^{12}$

\section{The Auction Mechanisms}

We study three different auction mechanisms for auctioning four units that represent the four licences. Two of these auction mechanisms proceed in two stages. The first stage consists of consecutive rounds of simultaneous bidding and ends when no more than five bidders remain. The second stage then consists of just one round of simultaneous bidding, where the four bidders with the highest bids receive the units. The difference between the two types of twostage auctions concerns the price the four winning bidders have to pay. In the uniform auction, they all pay the fourth highest bid; in the discriminatory auction each of the four highest bidders pays his own bid. The third auction mechanism is a simple English auction, which proceeds in consecutive rounds of simultaneous bidding until only four bidders remain. These remaining bidders receive the four units and each of them pays the fifth highest bid. The next section describes the auction mechanisms in more detail.

\subsection{The Two-Stage Auctions (Uniform and Discriminatory)}

The rules for both two-stage auctions were closely adapted from the rules suggested by RA. The only major modification concerned the pattern for the minimum increments. This pattern was modified in a manner that allowed us to increase the number of auctions within a session.

\footnotetext{
12 This is different from the assumptions of some other related models, in which the ex-ante weaker bidder knows for sure that he will have a private value disadvantage, e.g. KLEMPERER (1998), JEHIEL and MOLDOVANU (2000).
} 


\section{The Stages}

The uniform and the discriminatory auction both consist of two consecutive stages. Stage 1 proceeds in several rounds. At the beginning of each round, each bidder is informed about:

- the current price: in the first round the current price is randomly pre-determined ${ }^{13}$ and called reserve price; in all other rounds it is set equal to the sixth highest bid of the previous round;

- $\quad$ the number of active bidders of each type and their identification numbers: in the first round all eight bidders are active. In all other rounds, the active bidders are those who were active in the previous round and did not quit the auction (see below);

- $\quad$ the minimal bid: the minimal bid of the first round coincides with the current price of the first round; in all other rounds an increment is added to the current price. Table 1 presents the increments used, depending on the number of active bidders and the current price. $^{14}$

Table 1. Bidding Increments

\begin{tabular}{ccc}
\hline Number of active bidders & Current Price $(\mathrm{c})$ & Increment \\
\hline 8 & $\mathrm{c}=$ reserve price $(\mathrm{r})$ & +175 \\
& $\mathrm{r}+1 \leq \mathrm{c} \leq \mathrm{r}+175$ & +125 \\
& $\mathrm{r}+176 \leq \mathrm{c} \leq \mathrm{r}+300$ & +75 \\
& $\mathrm{c}>\mathrm{r}+300$ & +25 \\
\hline 7 & always & +20 \\
\hline 6 & always & +10 \\
\hline
\end{tabular}

\footnotetext{
${ }^{13}$ To speed up the experiment the random draw was positively correlated to the actual $c v c$, such that the relevant price range would be reached faster when the $c v c$ was high. However, subjects were not told about this correlation, and considerable noise was added in order to prevent that subjects could draw inference from the reserve price on the actual $c v c$.

${ }^{14}$ In spectrum auctions, the minimum increment is usually chosen as a certain percentage (e.g. 10 percent) that can be lowered by the auctioneer in later rounds. However, this pattern leads to very small absolute increases especially at early rounds when prices are still far away from the bidders' willingness-to-pay. On the other hand, a fixed percentage would lead to large absolute jumps in later rounds, such that many bidders would drop out in the same round.
} 
Each bidder has two possible actions:

- $\quad$ quit the auction: a bidder can quit the auction by either actively choosing the option to quit or by not submitting a bid during the round's decision time ${ }^{15}$. In general, a bidder who quits the auction is not able to re-enter (exceptions see below), or

- submit a bid: a bid is feasible for a certain bidder, if it is greater or equal to the minimal bid. In addition, bids must be no greater than a given maximum bid of 2000 (so-called "liquidity constraint"). The latter restriction prevents ruinously high bids possibly submitted by error.

The first stage of the auction ends as soon as either

- $\quad$ exactly three bidders have quit the auction at that stage: then the other five (still active) bidders proceed to the second stage; or

- more than three bidders have quit the auction at that stage: if this has happened in the first round, then all bidders who submitted a bid in the first round proceed to the second stage; if this has happened in a later round, all bidders who had submitted a bid in the round before the current one proceed to the second stage.

The second stage of the auction consists of only one round of bidding. Each bidder who has reached the second stage must submit a bid. The minimal bid equals the current price of the last round of the first stage. As before, the submitted bids cannot be smaller than the minimal bid. If a bidder refrains from submitting a bid within the provided decision time, it is assumed that this bidder has submitted a bid equal to the minimal bid.

\section{Allocation and Payments}

The allocation of the four units to the bidders of the second stage proceeds in one of two ways:

- uniform auction: the bidders with the four highest bids (ranks of equally high bids are assigned randomly with equal probabilities) receive the four units and each of them pays a price equal to the fourth highest bid, or

- discriminatory auction: the bidders with the four highest bids (ranks of equally high bids are assigned randomly with equal probabilities) receive the four units and each of them pays a price equal to his own bid.

\section{Information about Bids in the Two-Stage Auctions}

In both auction formats, after each round within an auction, all bidders are informed about the identity of those who submitted a bid. After each round in the first stage, the bidders are additionally informed about the current price. However, they are neither informed about the

\footnotetext{
15 In the beginning of a session the decision time was set to three minutes. Afterwards it was reduced to one minute. There was no indication that the subjects perceived the decision time as too short.
} 
identity of the bidders with the sixth highest bid (recall that from the second round on, the current price equals the sixth highest bid) nor about other bids.

After the second stage, all bidders are informed about the common value $c v c$ of a unit. In the discriminatory auction, they are informed about all final bids and the identity of the bidders. In the uniform auction, they are informed only about the fourth highest final bid (i.e. the price), the ranking of all final bids and the identity of the corresponding bidders.

Bidders who do not receive a unit neither gain nor lose. The payoff of a bidder who buys a unit is equal to the sum of the common value component and the private value component of the bidder minus the amount the bidder pays for the unit $(c v c+p v c-$ price).

\subsection{The English Auction}

The English auction proceeds in a single stage, which is analogous to the first stage of the two-stage auction versions, with the following exceptions:

- $\quad$ the current price (after the first round) is the fifth highest rather than the sixth highest bid of the previous round.

- $\quad$ as long as at least six bidders are active, the bidding increment is determined by table 1 , in the same way as in the first stage of a two-stage auction. Otherwise the bidding increment is +10 .

- $\quad$ the bidding continues until at least four bidders have quit the auction:

- $\quad$ if the number of bidders who have quit is four, the units are allocated to the four remaining bidders and each of them pays a price equal to the current price of the last round, i.e. equal to the fifth highest bid of the previous round.

- $\quad$ if the number of bidders who have quit exceeds four (this may happen if more than one bidder has decided to quit the auction in the preceding round), all remaining bidders receive a unit. The units left are then allocated randomly and with equal probability to those bidders who had simultaneously quit the auction in the preceding round. The price that all the purchasing bidders pay is equal to the current price.

- $\quad$ if the number of bidders who bid the reserve price in the very first round is smaller than four, these bidders receive a unit at the reserve price and no other units are sold.

- The information about the final bids is analogous to the information given in the uniform auction.

\subsection{The Experimental Design}

The experiment was conducted in October 1998 at the Laboratorium für experimentelle Wirtschaftsforschung at the University of Bonn. The experiment was computerised with 
software developed using RatImage (ABBINK and SADRIEH 1995). The three treatments were the three auction designs: uniform price auction, discriminatory price auction and English auction. The experimental subjects were students (mostly of law and economics) of the University of Bonn. They were paid according to their performance in the auction. The average pay per hour was about $22 \mathrm{DM}$, which is above the students' regular hourly wage rate. ${ }^{16}$ Each subject could only participate in one of the inexperienced sessions. In addition some subjects also participated in one of the experienced sessions. We report 9 sessions each with the uniform and the discriminatory auction, and 5 with the pure English format. ${ }^{17}$ With experienced subjects, we conducted 3 sessions with each of the Anglo-Dutch hybrids. In total 184 subjects participated in more than 400 auctions.

In most cases, 15 auctions were conducted in each inexperienced session and 20 in the experienced sessions. For the sake of comparability, several sets of random values were drawn in advance. Each such set is called a set-up and contains random signals for the $c v c$ and the $p v c s$ for all auctions of a session, independently drawn for each auction within a session. In total 12 different set-ups were used in the sessions. ${ }^{18}$ Nine set-ups $(1, \ldots, 9)$ in the inexperienced subjects' sessions and 3 set-ups in the experienced subjects' sessions. Each of the set-ups 1 to 5 was used for one session of the discriminatory auction, one session of the uniform auction, and one session of the English auction. Each of the other set-ups was used in only one session of the discriminatory auction and one session of the uniform auction. The fact that we held the set-up constant for one session of each auction type allows us to make direct comparisons, which are not affected by the realisations of the random variables.

The same eight subjects participated in each auction within a given session. The bidder type (INC or NEW) of each subject remained unchanged over all auctions of a session. At the beginning of the session, each subject received a capital balance to which gains were added and from which losses were subtracted. The total earnings of a subject in the experiment consisted of the sum of all payoffs from the auctions plus the capital balance. The sessions lasted between 3 and $3 \frac{1}{2}$ hours, which included detailed instructions of approximately 30 minutes. The written instructions (translated from German) that were handed out to the subjects are contained in the Appendix.

\section{Results}

In the following, we analyse the data of the experiment with respect to total surplus in the auction, the number of successful NEW-type bidders, the auction revenue, and the avoidance

\footnotetext{
${ }^{16}$ At the time of the experiment, DM 1 was approximately US-\$0.60 and $£ 0.35$.

${ }^{17}$ The experiments were conducted under an extremely tight time schedule, since strict deadlines had to be met for the submission of the results to RA. Therefore, only 5 observations in the pure English format with inexperienced subjects could be gathered.

${ }^{18}$ Due to serious language problems with the subjects of one session, which led to the completion of only 8 auctions, we decided to discard both sessions with the with the thirteenth set-up from the evaluation.
} 
of the winner's curse. These aspects of the outcomes are of particular interest because they are closely related to the goals described in the statements of the British government. The main objective repeatedly stated was the government's concern for overall efficiency and general welfare. $^{19}$

We run our statistical tests on the data from the sessions with inexperienced subjects. In order to account for a change of behaviour over time, we group the results of the auctions of each inexperienced session into three phases of 5 auctions (1-5, 6-10, 11-15). We run statistical tests for all phases of the sessions with inexperienced subjects, but we consider the last phase as the most representative of the behaviour of real bidders, because bidders in the UMTS auctions are expected to be very well-prepared professionals. Since only three observations of sessions with experienced subjects are available per treatment, statistical tests cannot be run for these data.

In the statistical analysis, the measures for the outcomes of the three auction mechanisms are compared pairwise for each of the three phases (runs 1-5, 6-10, 11-15). When comparing the discriminatory to the uniform auction, all nine sessions with inexperienced subjects are examined. When comparing the English to either of the other auction mechanisms, only the first five sessions with inexperienced subjects are examined to ensure comparability. We report the results of the binomial test. We have also applied other non-parametric tests; the results are not essentially different.

\subsection{Surplus}

We study total surplus as a measure of efficiency. The total surplus is the sum of the four buyers' valuations for the items, where a buyer's valuation is the sum of his private value component and the common value component. Total surplus is maximised when the licences are awarded to the bidders with the highest private value components. Figure 1 shows the average total surplus in the three auction formats for each of 15 auctions. All three formats are very similar in the average total surplus. No significant difference can be detected in any pairwise comparison of auction designs. This also holds for the comparison of the total surplus measures in the sessions with experienced subjects that are displayed in figure 2 . The strong correlation between the surpluses of the two treatments is due to the paired set-ups. The common value and private value components differ across rounds, but are the same across treatments for a given auction number.

\footnotetext{
${ }^{19}$ For a more detailed account of the government's objectives see DEPARTMENT OF TRADE AND INDUSTRY (1998).
} 


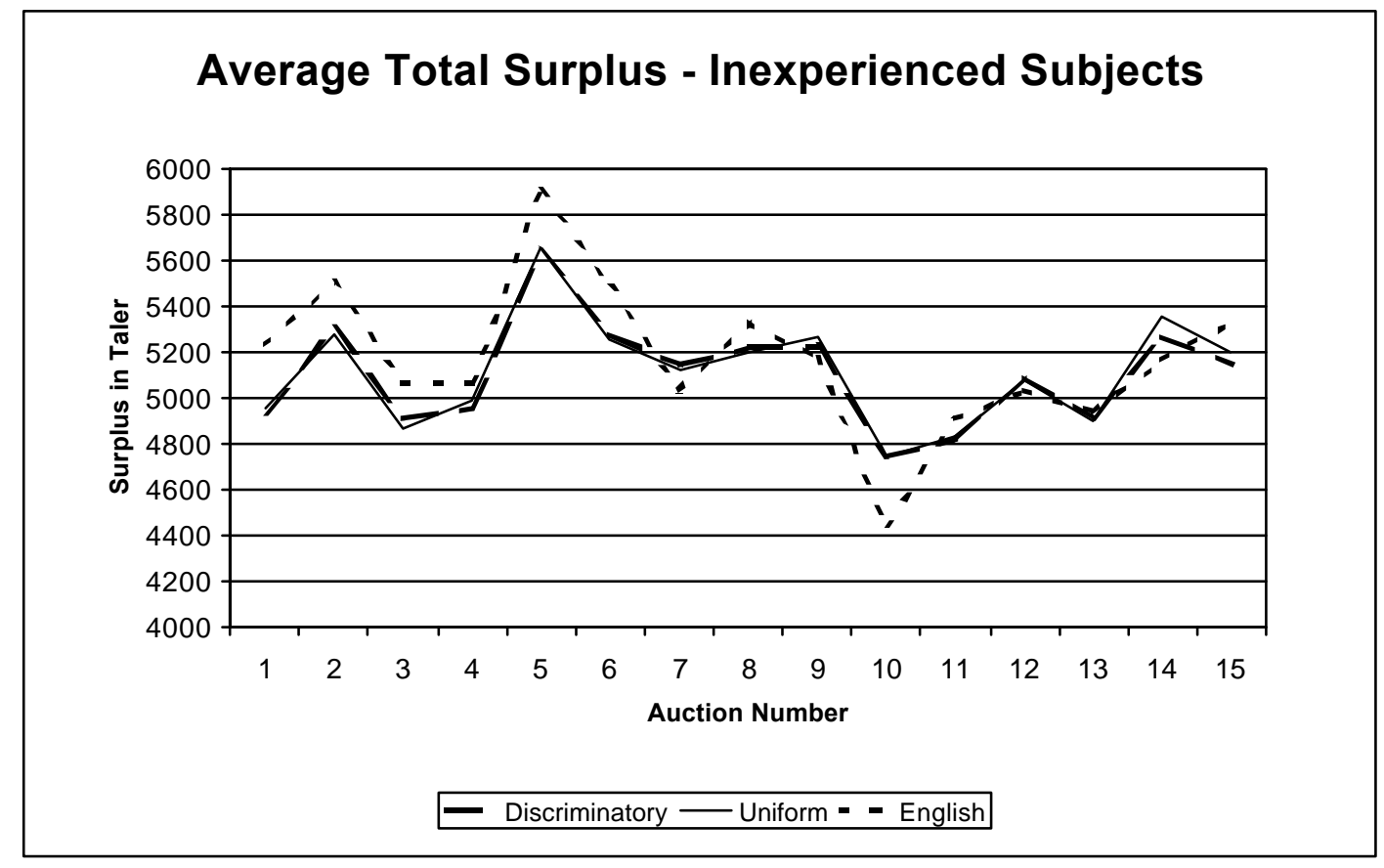

Figure 1

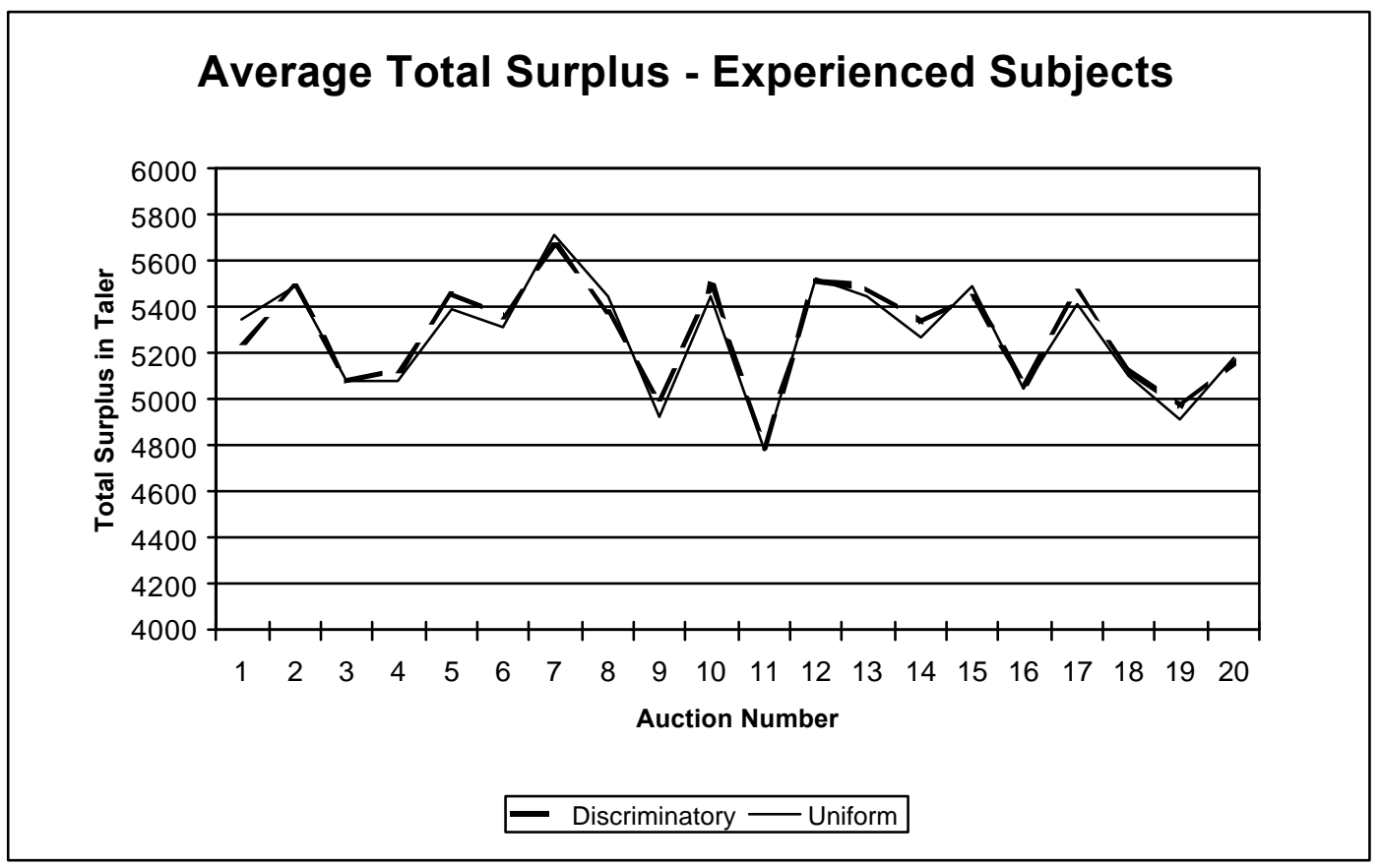

Figure 2

Table 2 shows percentage measures for the capacity of the auction designs to generate total surplus. Recall that the maximal surplus is realised if the four bidders with the highest values receive the licences. The surplus is minimised, given all four licences are sold ${ }^{20}$, if the four licences are awarded to the bidders with the lowest valuations. We therefore compute the

20 In principle, it is possible that licences remain unsold, if less than four bidders are willing to pay the reserve price. In this case, the total surplus can be even lower. In our experiments, however, this case never occurred. 
surplus extraction ratio as the difference between actual (act) and minimal ( $\mathrm{min}$ ) surplus, in relation to the difference between maximal (max) and minimal surplus, formally

$$
\frac{S^{a c t}-S^{\min }}{S^{\max }-S^{\min }} .
$$

The measure illustrates the percentage of excess surplus (in addition to the minimal surplus) that is extracted in the auction. The average surplus extraction ratios for the three auction formats are listed in table 2, computed for the later phase (rounds 11-15) and for all rounds of the sessions with experienced subjects. The surplus measures are highest for the discriminatory hybrid, while the uniform hybrid and the English auction perform very similarly. However, as for the absolute total surpluses, significant differences between any of the three designs cannot be detected.

Table 2. Total surplus extraction in the three auction formats

\begin{tabular}{cccc}
\hline Auction format & set-ups 1-5 & set-ups 1-9 & experienced \\
\hline Discriminatory & $74.9 \%$ & $72.5 \%$ & $76.8 \%$ \\
Uniform & $69.8 \%$ & $70.5 \%$ & $73.7 \%$ \\
English & $69.4 \%$ & - & - \\
\hline
\end{tabular}

\subsection{Chances for New Entrants to Purchase a Licence}

One major reason why the auction designers introduced the sealed-bid stage was that this was expected to favour new entrants. Our experimental data, however, do not support such expectations. Table 3 shows the average number of NEW-type bidders who purchase a licence in the last phase of the inexperienced sessions. ${ }^{21}$ The highest number of successful new entrants can be found in the English auction.

Table 3. Average number of new entrants buying a licence (last phase)

\begin{tabular}{cccc}
\hline set-up & discriminatory & uniform & English \\
\hline 1 & 2.0 & 1.3 & 2.0 \\
2 & 1.6 & 1.8 & 1.8 \\
3 & 1.2 & 1.6 & 1.4 \\
4 & 1.6 & 1.6 & 2.0 \\
5 & 1.4 & 1.8 & 2.2 \\
\hline Average & 1.52 & 1.65 & 1.87 \\
\hline
\end{tabular}

21 Recall that the NEW-type bidders are ex-ante disadvantaged, but not necessarily ex-post. 
In all five set-ups conducted with the English auction design, the number of successful new entrants is at least as high as under the discriminatory Anglo-Dutch hybrid. The difference is weakly significant at $p=0.06$ (one-sided), according to the binomial test. The differences between the English and the uniform auction and between the two hybrids are not significant.

\subsection{Revenue}

Revenue was mentioned as one of the goal variables of the British government. ${ }^{22}$ The revenue is the sum of prices paid by the four buyers. Figure 3 shows the average revenue generated in the up to 15 repetitions of the auction in the experiment with inexperienced subjects. Figure 4 depicts the analogous for the experienced sessions.

In the beginning of an inexperienced session, the discriminatory auction has a clear and significant revenue advantage over the uniform auction. The pure English auction yields weakly significantly higher revenue than both hybrids in the second phase. However, as bidders get experienced, the differences diminish. Towards the end of the experiment, no significant differences in revenue can be detected between the three auction designs. Interestingly, the similarity in revenue between the two hybrids remains stable in the experienced sessions, as figure 4 shows. Again, the use of the same set-ups for the treatments induces a pronounced correlation between the graphs. Significant differences of the average revenue in each phase (the five run average) are presented in table 4.

The revenue advantage of the discriminatory over the uniform auction in the early phase of the experiment can be explained with inexperienced bidders submitting bids close to their signal. Then, the feature of the uniform auction to charge every winner only the fourth highest bids leads to less revenue. However, it is interesting that the pure English auction does not yield less revenue than the discriminatory format, though it shares the characteristic of a oneprice auction with the uniform hybrid. Apparently, the English auction induces quite aggressive bidding behaviour right from the start of the experiment.

Next to the expected revenue, a risk-averse auctioneer would favour a secure revenue expectation. Note that the real UMTS auction is a one-shot game. Therefore, we computed also the revenue spread, the difference between the minimal and the maximal revenue achieved within the five runs of an experience phase. We find a weakly significantly lower revenue spread in the uniform than in the discriminatory auction (one-tail $p=0.07$, according to the binomial test) in the last experience phase. No significant difference could be observed between of the hybrids and the ascending price format.

\footnotetext{
${ }^{22}$ Government officials repeatedly emphasised that revenue maximisation was not the primary goal.
} 


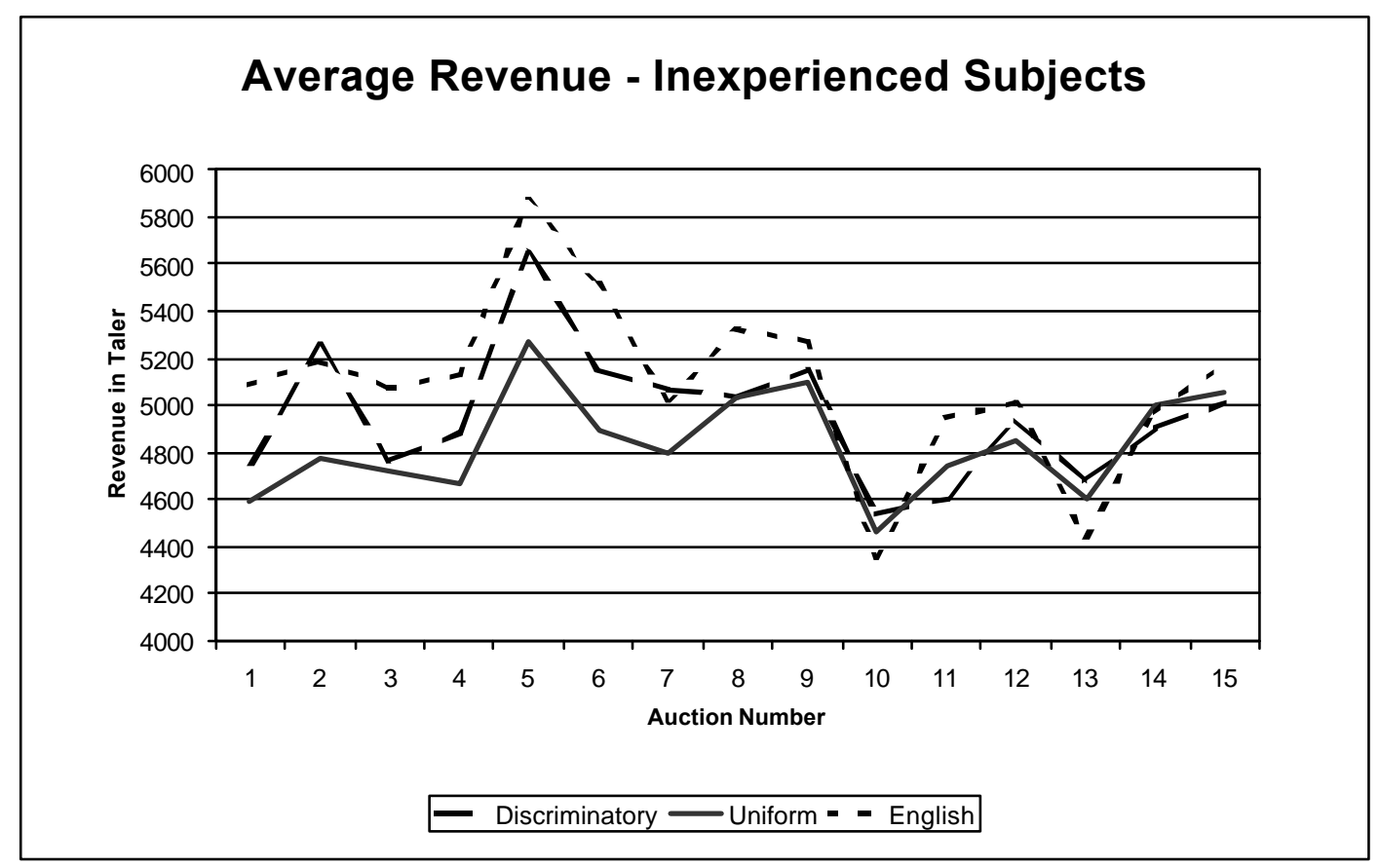

Figure 3

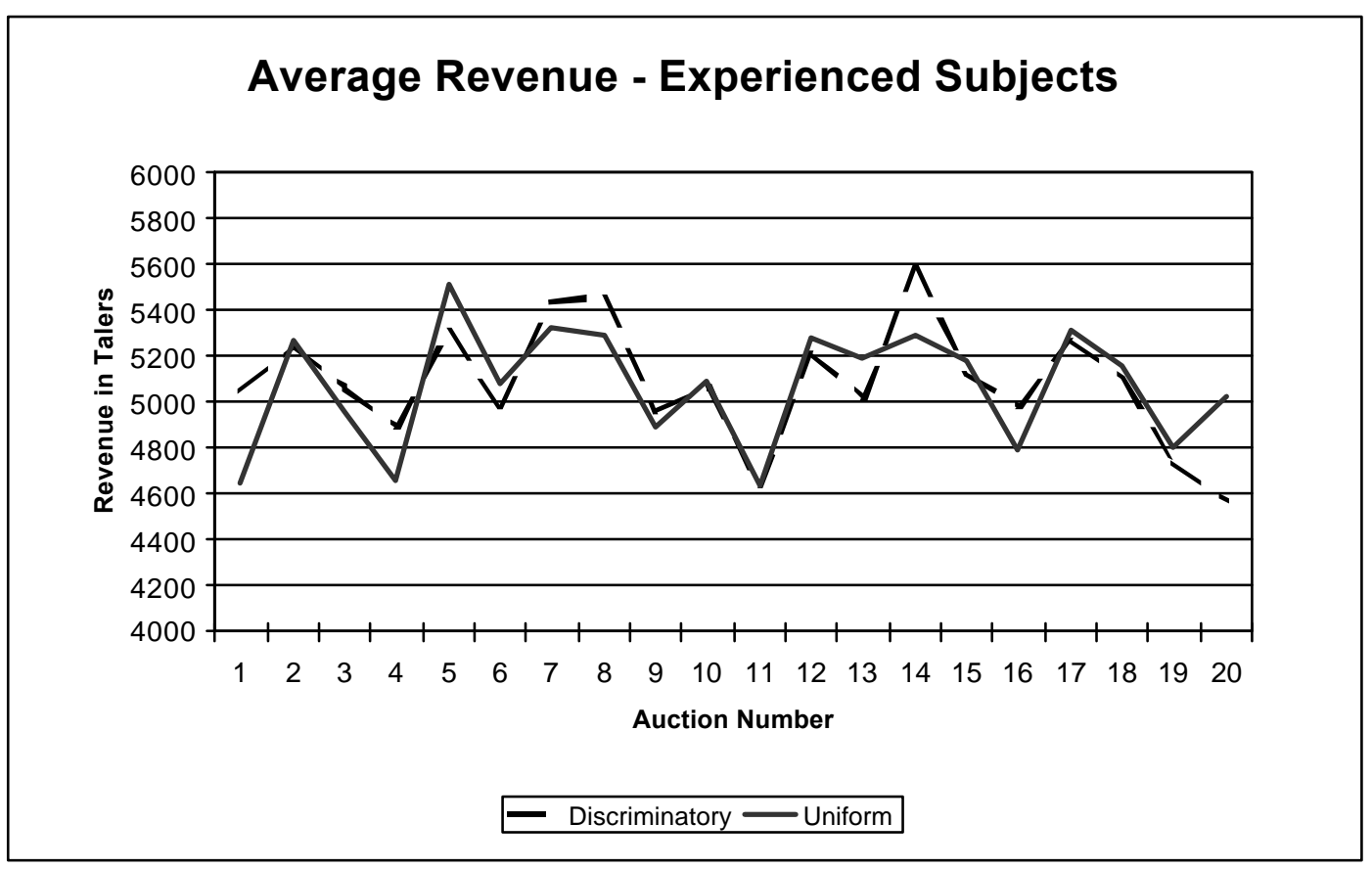

Figure 4 
Table 4. Significant Differences in Average Revenue

\begin{tabular}{cccc}
\hline $\begin{array}{c}\text { five run } \\
\text { average revenue }\end{array}$ & \multicolumn{2}{l}{ Experience Phase } \\
\hline & $1-5$ & $6-10$ & $11-15$ \\
\hline D vs. U & $\mathrm{D}_{1}>\mathrm{U}_{1}(0.01)$ & $\mathrm{D}_{2}>\mathrm{U}_{2}(0.03)$ & - \\
D vs. E & - & $\mathrm{D}_{2}<\mathrm{E}_{2}(0.09)$ & - \\
U vs. E & - & $\mathrm{U}_{2}<\mathrm{E}_{2}(0.06)$ & - \\
\hline
\end{tabular}

(In brackets are the one-tail p-values according to the binomial test)

\subsection{Winner's Curse}

A buyer suffers from the winner's curse, if he/she overpays, i.e. if the price paid is higher than the $c v c$ plus the buyer's $p v c$. Recall that the bidders were not informed about the $c v c$, so that prior to buying, a bidder typically was unaware that he/she had offered to pay too much. Though the winner's curse induces a tendency towards high revenue, the phenomenon is very undesirable for the government as the auctioneer. The C-block auction held in 1996 by the FCC in the United States left the US government with a number of defaulting buyers who failed to fulfil the obligations from their exaggeratedly high bids. Further, next to the licence costs high investments by the licensees are required. Thus, avoiding the winner's curse phenomenon seems desirable for a spectrum auction designer.

We do not find significant differences in the occurrences of the winner's curse in the last experience phase. In the first and the second experience phase, we observe significantly more winner's curses in the discriminatory than in the uniform auction (one-tail $p=0.07, p=0.02$ resp., according to the binomial test). This supports the findings about the revenue differences between these two auction formats. The uniform auction induces lower prices (thus less revenue and fewer winner's curses) in the beginning, but the difference disappears with experience.

\section{Conclusions from the experiment}

We compared two auction formats suggested by the British government for the 3G/ UMTS licence auction in the UK. In addition, we compared both designs to a more traditional English auction design. With respect to the main goals of high economic efficiency, good chances for new entrants, high revenue, and winner's curse avoidance, we find only small differences. Moreover, these differences vanish in later rounds, which are most representative of the real situation. The most striking finding is that all three formats induce remarkably little revenue differences in later rounds of the experiments. When bidders are sufficiently experienced, all three formats seem to be "experimentally revenue equivalent". ${ }^{23}$

\footnotetext{
${ }^{23}$ The famous revenue equivalence theorem by VICKREY (1961) states that in equilibrium expected revenue is the same in Dutch and English single-unit auctions when buyers are risk neutral and have independent private values. MILGROM and WEBER (1982) show this result holds for multi-unit auctions (i.e., Uniform,
} 
Our experimental results suggest that the novel Anglo-Dutch auction designs are neither more nor less efficient or revenue generating than the ascending auction formats. The claim that the sealed-bid stage favours new entrants could not be supported. On the contrary, we observed the highest number of successful new entrants with the English auction, weakly significantly more than in the discriminatory hybrid. All three designs show similar performance in protecting bidders from the winner's curse in the last experience phase.

We believe our experimental results to be indicative for the performance of the three designs. However, they cannot be conclusive for spectrum auctions in general, since our experiment was designed for the specific UK situation. In other auctions for mobile telephony licensing, the situation may be different with respect to spectrum packaging or market structure, so that different auction designs may be appropriate. Before a spectrum auction is held, evidence from experiments tailored to the particular environment should be sought.

\section{Further Development}

The results of the experiment were reported to RA by the auction participant who commissioned this work. In the process of the licensing not only the auction design, but also the frequency packaging of the licences was changed. The British government decided to award five licences instead of four. These packages could not be homogeneous anymore because the 2x60 MHz paired and $20 \mathrm{MHz}$ unpaired spectrum available for $3 \mathrm{G}$ services can only be divided into blocks of $5 \mathrm{MHz}$ bandwidth. The spectrum was assigned to the licences as listed in table $5 .^{24}$

The auction design chosen to sell the five licences was a traditional ascending auction format. In every round, each bidder could place a bid on one of the five licences, where the incumbents were not allowed to bid on licence A. When a bidder was overbid on a licence, he had to bid in order to stay in the process, but he was free to switch between the licences. A bidder standing high on a licence was not allowed to bid until he was overbid again. The auction ended when all but the five bidders finally standing high on the licences had withdrawn. A sealed-bid stage was not conducted. ${ }^{25}$

Discriminatory, English (sequential or not), First- and Second-Price auctions) under the same assumptions if buyers have unit demands.

\footnotetext{
${ }^{24}$ The spectrum assigned to a licence does not directly correspond to its capacity, but rather determines the costs at which services can be provided. In principle, it is possible to increase the capacity of spectrum by installing a narrower network of base stations. However, this requires additional investment. Thus, the owner of a large licence (A or B) can be expected to have fixed cost advantages. Whether the lacking block of unpaired spectrum of licence B is relevant for its value is not clear. Unpaired spectrum can be used only if traffic is predominantly asymmetric. Its value depends on the future demand for asymmetric data transmission and on future technology.

${ }^{25}$ KLEMPERER (2000) reports that a straightforward ascending design was no longer considered counterindicated because after the switch to five licences it was ensured that at least one new entrant would win a licence.
} 
Table 5. Assignment of spectrum to licences

\begin{tabular}{cccc}
\hline licence & paired spectrum & unpaired spectrum & \\
\hline A & $2 \times 15 \mathrm{MHz}$ & $1 \times 5 \mathrm{MHz}$ & (reserved for new entrant) \\
B & $2 \times 15 \mathrm{MHz}$ & - & \\
C & $2 \times 10 \mathrm{MHz}$ & $1 \times 5 \mathrm{MHz}$ & \\
D & $2 \times 10 \mathrm{MHz}$ & $1 \times 5 \mathrm{MHz}$ \\
E & $2 \times 10 \mathrm{MHz}$ & $1 \times 5 \mathrm{MHz}$ \\
\hline
\end{tabular}

Thirteen bidders participated in the auction, next to the four incumbents (Vodafone, British Telecom, Orange, and One2One) there were nine bidders mainly constituted by foreign telecommunications operators. The auction process started in March 2000 and was completed after six weeks and 150 rounds. The allocation of the licences and the selling prices are shown in table $6 .^{26}$

Table 6. The result of the UK-UMTS auction

\begin{tabular}{ccc}
\hline Licence & Winner & Price $(£)^{27}$ \\
\hline A & TIW & $4.385 \mathrm{bn}$ \\
B & Vodafone & $5.964 \mathrm{bn}$ \\
C & British Telecom & $4.030 \mathrm{bn}$ \\
D & One2One & $4.003 \mathrm{bn}$ \\
E & Orange & $4.095 \mathrm{bn}$ \\
\hline Total revenue & & $22.477 \mathrm{bn}$ \\
\hline
\end{tabular}

\footnotetext{
${ }^{26}$ For an ex-post analysis of the $3 \mathrm{G} / \mathrm{UMTS}$ auction in the United Kingdom auction see PLOTT and SALMON (2001).

${ }^{27}$ At the time of the auction, $£ 1$ was approximately EUR 1.69 and US-\$1.63.
} 


\section{References}

ABBINK, K., and A. SADRIEH (1995): RatImage - Research Assistance Toolbox for Computer-Aided Human Behavior Experiments. SFB Discussion Paper B-325, University of Bonn.

AVERY , C., and J. KAGEL (1997): Second-Price auctions with asymmetric payoffs: An experimental investigation. Journal of Economics \& Management Strategy, 6(3), 573-603.

Ausubel, L.M., P.C. CRAMTON, P.R. MCAFEe, and J. MCMiLlan (1997): Synergies in Wireless Telephony: Evidence from the Broadband PCS Auctions. Journal of Economics \& Management Strategy, 6:3, 7-71.

BIKHCHANDANI , S. (1988): Reputation in Repeated Second-Price Auctions. Journal of Economic Theory, 46, 97-119.

Bulow, J., HuAng, L., and P. KLEMPERER (1998): Toeholds and Takeovers. Journal of Political Economy, 107, 427-454.

BulOW, J., and P. KLEMPERER (2000): Prices and the Winner's Curse. Mimeo. Oxford University.

CAPEN, E.C., R.V. ClAPP, and W.M. CAMPBELL (1971): Competitive bidding in high-risk situations. Journal of Petroleum Technology, 23, 641-53.

CASSADY R. JR. (1967): Auctions and Auctioneering. California University Press.

CRAmTON, P.C. (1995): Money out of Thin Air: The Nationwide Narrowband PCS Auction. Journal of Economics \& Management Strategy, 4, 267-343.

DEPARTMENT OF TRADE AND INDUSTRY (1998): Mobile Multimedia Communications. DTI Press Release, 18 May 1998.

DE Frutos, $\mathrm{M}^{\mathrm{a}}$.A. and L. PeChlivanos (2001): Second-Price Common-Value Auctions under Multidimensional Uncertainty. Mimeo, Universidad Carlos III de Madrid.

GoEREE, J. and T. OFFERMAN (2001): Efficiency in Auctions with Private and Common Values: An Experimental Study. American Economic Review, forthcoming.

Jehiel, P. and B. Moldovanu (2000): A Critique of the Planned Rules for The German UMTS/IMT-2000 License Auction. Discussion paper, University of Mannheim.

KAGEL, J.H. (1995). Auctions. In J.H. KAGEL and A.E. ROTH (eds.): Handbook of Experimental Economics. Princeton University Press.

KAgEL J.H. and LEVIN D. (1986), "The Winner's Curse and Public Information in Common Value Auctions", American Economic Review, 76:5, 894-920

KAMECKE, U. (1998a): Competition, Cooperation, and Envy in a Simple English Auction. Mimeo, Humboldt University at Berlin.

KAMECKE, U. (1998b): Dominance or Maximin: How to solve an English Auction. International Journal of Game Theory, 27, 407-426.

Klemperer, P. (1998): Auctions with Almost Common Values: The 'Wallet Game' and Its Applications. European Economic Review; 42(3-5), 757-69.

KLEMPERER, P. (2000): What Really Matters in Auction Design. Mimeo. Oxford University.

KEUTER, A., and L NETT (1997): ERMES-Auction in Germany: First Simultaneous Multiple-Round Auction in the European Telecommunications Market. Telecommunications Policy; 21:4, 297-307.

MCAFEE, P.R., and J. MCMillan (1996): Analyzing the Airwave Auction. Journal of Economic Perspectives, $10,159-175$.

MCMillan, J. (1994): Selling Spectrum Rights. Journal of Economic Perspectives, 8, 145-162.

MiLGROM P.R. and R. WEBER (2000): A theory of auctions and competitive bidding, Part 2. In P. KLEMPERER (ed.): The Economic Theory of Auctions. Vol. 2. Edward Elgar Publishing.

PLOTT C.R. (1997): Laboratory Experimental Testbeds: Application to the PCS Auction. Journal of Economics \& Management Strategy; 6:3, 605-638.

PlotT, C.R., and T.C. SAlMON (2001): The Simultaneous, Ascending Price Auction: Dynamics of Price Adjustment in Experiments and in the Field. Mimeo, CalTech.

RoBINSON, M.S. (1985): Collusion and the Choice of Auction. RAND Journal of Economics, 16, 141-145.

SALANT, D.J. (1997): Up in the Air: GTE's Experience in the MTA Auction for Personal Communication Services Licenses. Journal of Economics \& Management Strategy, 6:3, 549-72.

VAlletti, T.M, and M. CAVE (1998): Competition in UK Mobile Communications. Telecommunications Policy, 22:2, 109-31.

VAN DAMME, E. (1999): The Dutch DCS-1800 auction. CentER Working paper 9977, Tilburg University.

VICKREY, W (1961): Counterspeculation, auctions, and competitive sealed tenders. Journal of Finance, 16, 8-37. 


\section{Appendix. The Written Instructions}

(The following instructions, which were read aloud to the subjects, were originally in German.)

\section{THE R ULES IN THE AUCTION EXPERIMENT}

\section{GOODS, BIDDERS, AND VALUES}

- Four units of a good can be bought in the auction. The units are indistinguishable.

- Eight bidders take part in the auction. Each bidder can buy one unit of the good at most.

- Each of the units has a common value that is identical for all units. The bidders are not informed of the common value during the auction. Each bidder receives an estimate of the common value, which is randomly drawn from the range \pm 200 around the common value. Each bidder receives a individual estimate of the common value, i.e. the estimates of the bidders will typically be different from one another.

- Each bidder is informed on his/her additional personal value, which he/she receives upon purchasing a unit of the good. The bidders' additional personal values will usually be different from one another. They all lie in the interval $[-100, \ldots,+100]$. There are two different types of bidders. The additional personal values of the P-Type bidders lie in the interval $[0, \ldots,+100]$ with a probability of $80 \%$ and in the interval $[-100, \ldots, 0]$ with a probability of $20 \%$. The additional personal values of the M-Type bidders lie in the interval $[-100, \ldots, 0]$ with a probability of $80 \%$ and in the interval $[0, \ldots,+100]$ with a probability of $20 \%$. The values within each of the intervals are equally likely to be drawn. Note that the additional personal value is not an estimate.

\section{[STAGES OF THE AUCTION}

- The auction proceeds in two consecutive stages. Typically five of the eight bidders are selected in stage 1 to bid for the four units in stage 2.] $]^{\text {Discriminatory and Uniform }}$

\section{[1ST STAGE OF THE AUCTION] $]^{\text {Discriminatory and Uniform }}[\text { ROUNDS OF THE AUCTION] }]^{\text {English }}$}

- At the outset of the auction, each bidder is informed of the maximal amount he/she is permitted to bid, i.e. of his/her liquidity.

- $\quad$ [Stage 1 consists of a number of rounds. $]^{\text {Discriminatory and Uniform }}$ Before each round, every bidder is informed of the current price and the identity of the bidders who have not yet quit the auction.

- $\quad$ The current price is set to the minimal sales limit, in the first round. The minimal sales limit is randomly drawn. In later rounds, the current price will be equal to the $[\text { sixth }]^{\text {Discriminatory and Uniform }}[\text { fifth }]^{\text {English }}$ highest bid of the round before.

- The minimal bid for the current round is announced at the beginning of each round. In the first round, the minimal bid is equal to the minimal sales limit. In the following rounds, the minimal bid is raised according to a pre-determined scheme.

- Within the given decision time of a round, a bidder can either quit the auction or submit a bid no smaller than the minimal bid and no greater than his/her liquidity. If a bidder lets the decision time elapse, it is assumed that he/she has decided to quit the auction.

[- The first stage of the auction ends when exactly five bidders are left who have not quit the auction. These five bidders proceed to the second stage. $]^{\text {Discriminatory and Uniform }}$

[- The auction ends when exactly four bidders are left who have not quit the auction. The remaining bidders acquire a unit at the current price. $]^{\text {English }}$ 
- If a bidder has quit the auction, he/she will in general be out of the auction for good, i.e. not be able to buy a unit of the good. This rule, however, will not be applied if the application would result in less than [five $]^{\text {Discriminatory and Uniform }}[\text { four }]^{\text {English }}$ bidders being left in the auction. [In such cases, the first stage will end and all bidders who had submitted a bid in the previous round will proceed to the second stage.] $]^{\text {Discriminatory and Uniform }}$ [In such cases, all bidders who had submitted a bid in the current round will acquire a unit. The remaining units will be distributed amongst those bidders who had submitted a bid in the previous round by randomly selecting as many of them as necessary. All bidders who acquire a unit pay the current price. $]^{\text {English }}$

[• Exception: If less than five bidders submit a bid in the first round, the first stage ends and those bidders who have submitted a bid will proceed to the second stage. $]^{\text {Discriminatory and Uniform }}$

[- Exception: If less than four bidders submit a bid in the first round, the auction ends. Those bidders who submitted a bid acquire a unit at the minimal sales price. $]^{\text {English }}$

\section{[2ND Stage OF THE AUCTION}

- There is only a single round in the second stage. Bidders who have proceeded to the second stage cannot quit the auction anymore.

- $\quad$ The minimal bid of the second stage is equal to the last current price of the first stage.

- $\quad$ Each bidder must submit a final bid. Each bid must be at least as great as the minimal bid. If a bidder chooses to let the decision time elapse without submitting a bid, it is assumed that he/she has submitted the minimal bid.

- The bidders will be sorted by the increasing order of their bids. If a number of bidders have submitted equal bids, the corresponding ranks of the bidders with equal bids are distributed randomly amongst them. The four bidders with the highest ranks receive a unit of the good at a price equal to [the bid they have submitted] Discriminatory [the bid submitted by the bidder with the fourth highest rank] $]^{\text {Uniform }}$.

- The [bidders and bids] $]^{\text {Discriminatory }}[\text { ranks of the bidders] }]^{\text {Uniform }}$ are announced. $]^{\text {Discriminatory and Uniform }}$

\section{PAYOFFS}

- Each participant will receive an endowment in Taler.

- A bidder who acquires a unit receives the common value of the unit plus his/her own additional personal value minus the price he/she has to pay for the unit.

- Note that losses are possible in an auction. This will be the case, if one pays more for the acquired unit than the sum of the common value and the additional personal value. Particularly note that your estimate can be higher than the common value.

- After the experiment, your Taler credit will be handed to you in DM with the exchange rate being DM 3 for each 100 Taler.

\section{NUMBER OF AUCTIONS}

- We will attempt to run 15 auctions in the available time. You will participate together with the same other seven bidders in all auctions. Each bidder is of the same type (P or $\mathbf{M})$ in all auctions. The units' common values, your estimates, and your additional personal values are drawn completely independent of the preceding auctions and will usually be different from one another for different auctions. 